Working Paper 02-29

Economics Series 10

May 2002
Departamento de Economía Universidad Carlos III de Madrid

Calle Madrid, 126 28903 Getafe (Spain)

Fax (34) 916249875

\title{
NONLINEAR MONETARY POLICY RULES: SOME NEW EVIDENCE FOR THE US *
}

\author{
J. J. Dolado ${ }^{a}$, R. M aria-Dolores ${ }^{b}$ and F. J. Ruge-M urciac
}

\begin{abstract}
This paper dreives optimal monetary policy rules in setups where certainty equivalence does not hold because either central bank preferences are not quadratic, and/or the aggregate supply relation is nonlinear. Analytical results show that these features lead to sign and size aymmetries, and nonlinearities in the policy rule. Reduced-form estimates indicate that US monetary policy can be characterized by a nonlinear policy rule after 1983, but not before 1979 . This finding is consistent with the view that the Fed 's inflation preferences during the VolckerGreenspan regime differ considerably from the ones during the Burns-M iller regime.
\end{abstract}

Keywords: nonlinear Taylor rules, inflation targets, asymmetric preferences, nonlinear Phillips curve, monetary policy.

\section{JEL Clasification: E52.}

a Departamento de Economía, U niversidad Carlos III de Madrid and CEPR, Spain; E.mail: dolado@eco.uc3m.es

b Departamento de Fundamentos del Análisis Económico, Universidad de Murcia, Spain; E.mail: ramonmar@um.es

c U niversité de M ontréal, Département de Sciences Économiques and CIREQ, C. P. 6128, succursale Centre-ville, Montreal (Québec) H3C3J7, Canada; E.mail: francisco.rugemurcia@umontreal.ca

* We thank Pedro Álvarez-L ois for helpful comments on an earlier version of this paper. The first author acknowledges the hospitality of the U niversity of M ontréal. The third authors thanks the Social Sciences and Humanities Research Council (Canada) and the Fonds pour la Formation de Chercheurs et I'A ide à la R echerche (Québec) for financial support. 


\section{Introduction}

This paper derives and estimates optimal monetary policy rules in a setup where certainty equivalence does not hold. In particular, our approach combines two different strands of the literature on monetary policy rules that depart from the standard linear-quadratic framework because either $(i)$ central bank preferences are not quadratic, or ( $i i)$ the aggregate supply relation is nonlinear.

As it is well known [see, for example, Svensson (1997) and Clarida et al. $(1999,2000)$ ], the combination of a quadratic loss function and a linear aggregate supply constraint leads to a linear reaction function (or Taylor rule) by the central bank. The optimal policy rule implies that the nominal short-term interest rate under the central bank's control is a linear function of the inflation and output gap deviations from their respective targets. Depending on the backward or forward nature of wage and price setting, and on assumptions regarding the information available to the central bank, both variables appear in the rule either in current terms or as expectations of their future values. Because they provide a reasonably good description of policy, linear rules have become a key element of diagnosis in the toolkit of monetary-policy analysts.

Recently, there have been a number of studies that seek to extend this traditional setup. The generalizations fall in two groups. First, Nobay and Peel (1998), Cukierman (1999), Gerlach (1999), and Ruge-Murcia (2001, 2002) relax the assumption of a quadratic central bank loss function and adopt instead asymmetric preference specifications. Their functional forms allow different weights for positive and negative inflation and/or output deviations from their target. Asymmetric preferences modify some of the results previously derived in the linear-quadratic framework.

For example, Cukierman (1999) shows that when the central bank is more concerned about under- than over-employment and there is uncertainty regarding future realizations of inflation and unemployment, an inflation bias can arise even if the unemployment target is the natural rate. Cukierman's proposition is examined empirically by Ruge-Murcia using cross-section data from OECD countries [Ruge-Murcia (2001)] and time series data from G7 countries [Ruge-Murcia (2002)] with encouraging results. Since the assumption that the central bank aims at a lower unemployment rate than the natural rate has been challenged on theoretical and institutional grounds [see Blinder (1998) and McCallum (1995, 1997)], this avenue of research seems promising.

Second, Schaling (2000) and Dolado et al. (2001) study models where the aggregate supply curve is not linear, but convex. In particular, the difference between realized and expected inflation is a convex function of the output gap. The underlying idea behind 
this specification goes back to the traditional Keynesian assumption that nominal wages are flexible upwards but rigid downwards, implying that inflation is a decreasing and convex function of the unemployment rate. This implies that an increase in unemployment will drive inflation down by much less when unemployment is high than when it is low [see Layard et al. (1991), Clark and Laxton (2000), and Álvarez-Lois (2001)]. If unemployment and the output gap are related through Okun's law, then a convex relationship between inflation and the output gap is a natural generalization of the linear aggregate supply. Combined with a quadratic loss function, the optimally-derived Taylor rule has nonlinear features: it implies that the central bank will increase interest rates by a larger amount when inflation is above target than it will reduce them when inflation is below target.

In line with the above discussion, the goal of this paper is to construct and estimate a more general model that combines both asymmetric central bank preferences and a non-linear Phillips curve. This is important for several reasons. First, it allows the joint analysis of two departures from the linear-quadratic setup that until now have been studied separately in the literature. Second, it permits us to trace back nonlinearities and asymmetries in the nominal interest rate to either central bank preferences, nonlinearities in the supply curve, or both. Finally, parameter estimates will indicate the relative importance of these two elements in monetary policy making.

In order to make the analysis tractable, we make a number of simplifying assumptions. These assumptions allow us to obtain an econometric specification of a Taylor rule where departures from the usual linear-quadratic model can be identified. First, we take as starting point the case of inflation targeting with no output-stabilization term appearing in the central bank's loss function. The reason for choosing this restricted specification is that it yields a closed-form solution for the optimal policy rule, that is not possible to obtain when the additional output goal is also considered. However, Svensson (1997) points out that allowing for the latter term does not change the form of the policy function, although it reduces the interest-rate response by the central bank to inflation and the output gap. Since our main interest is in identifying departures from the standard reaction function and not in the size of the coefficients themselves, we believe that the adopted assumption is not too restrictive for the purpose at hand.

Second, we adopt a backward-looking specification of the IS and AS schedules in the theoretical part [as Svensson (1997)], rather than a forward-looking specification as the one proposed by Clarida et al. (1997, 1999, 2000). Again, the reason for adopting this formulation of the aggregate baseline model is analytical tractability. The basic advantage of a forward-looking specification is that it does not require the assumption that the central bank is "over-ambitious" with respect to output in order to generate benefits from commitment 
[see Clarida et al. (1999)]. Since we do not tackle that issue directly in this paper, we believe that the adopted specification is not too restrictive in this regard.

The contributions of this paper are twofold. From an analytical viewpoint, we construct a model of inflation targeting where the central bank's preferences are asymmetric and the aggregate supply curve is nonlinear. Preferences are asymmetric in the sense that positive deviations from the inflation target can be weighted more (or less) severely than negative deviations in the central bank's loss function. The aggregate supply curve is an increasing and convex function of the output gap. In this manner, we are able to derive a Taylor rule in a nonlinear framework that generalizes the usual specification in the literature where the objective function is quadratic and constraints are linear.

From an empirical viewpoint, we confront the new Taylor rule with data on short-term interest rate interventions by the US Federal Reserve. Reduced-form estimates indicate that US monetary policy can be characterized by a nonlinear rule after 1983, but not before 1979. Although we do not find evidence in favor of a convex aggregate supply curve, we do find evidence consistent with asymmetric inflation preferences on the part of the US Federal Reserve after 1983. This suggests that the Fed's inflation preferences during the VolckerGreenspan regime differ considerably from the ones during the Burns-Miller regime. When we compare our results with those of Clarida et al. (2000) using a linear Taylor rule for the post-1982 period, we do not find evidence that the response of the short-term interest rate to inflation was larger than unity once asymmetric preferences are allowed for. The reason for this result is that under asymmetric preferences, the targeted interest rate depends on the conditional variance of inflation, that in turn depends nonlinearly on lagged inflation. The response of the interest rate to inflation depends on a linear part and a nonlinear part such that the overall response is most likely stabilizing, as suggested by Clarida et al. However, the interpretation of how stabilization was achieved in the Volcker-Greenspan era is different in both models.

The rest of the paper is structured as follows. Section 2 derives the form of the nonlinear policy rule under the general case of asymmetric preferences and a convex aggregate supply curve, and compares it to several relevant subcases. Section 3 estimates the nonlinear rule for the US, distinguishing between the two relevant subperiods and using a wide array of alternative specification to check the robustness of the results. Finally, Section 4 concludes. An Appendix contains a detailed derivation of the nonlinear monetary policy rule. 


\section{A Simple Model}

In order to fix ideas, it is helpful to consider a simple model of optimal monetary policy. The model follows closely the one proposed by Svensson (1997), but generalizes the specification of the central bank preferences and aggregate supply curve in a manner to be made precise below. Although Section 3 reports estimates of the policy rule obtained using this model, it also shows that the main finding of this paper is robust to the precise form of the rule (for example, whether forward or backward looking).

Assume that monetary policy is conducted by a central bank that chooses the sequence of short-term interest rates that minimizes the present discounted value of its loss function. The loss function depends on the distance between realized inflation and its socially optimal rate. Formally, the central bank's problem is

$$
\underset{\left\{i_{t+s}\right\}_{s=0}^{\infty}}{\operatorname{Min}} E_{t} \sum_{s=0}^{\infty} \beta^{s} L\left(\pi_{t+s}-\pi^{*}\right) \text {, }
$$

where $i_{t}$ is the nominal interest rate, $0<\beta<1$ is the discount rate, $\pi_{t}$ is the inflation rate, $\pi^{*}$ is socially-optimal inflation rate, and the loss function $L(\cdot)$ takes the form:

$$
L\left(\pi_{t}-\pi^{*}\right)=\frac{\left.\left.\exp \left(\gamma\left(\pi_{t}-\pi^{*}\right)\right)-\gamma\left(\pi_{t}-\pi^{*}\right)-1\right)\right)}{\gamma^{2}}
$$

This loss function corresponds to the linex function, originally proposed by Varian (1974). This function has several important properties. First, it permits different weights for positive and negative inflation deviations from $\pi^{*}$. Consider the case where $\gamma>0$. For inflation rates below $\pi^{*}$, the linear term becomes progressively more important as inflation decreases and, consequently, the loss rises linearly. For inflation rates above $\pi^{*}$, it is the exponential term that eventually dominates and the loss associated with a positive deviation rises exponentially. Hence, positive deviations from $\pi^{*}$ are weighted more severely than negative ones in the central banker's loss function. Second, it predicts that both the size and sign of a deviation affect the central banker's loss. In contrast, under quadratic preferences, the loss is completely determined by the size of the deviation. Third, it relaxes certainty equivalence and allows a prudence motive on the part of the central banker. Then, moments of higher order than the mean might play a role in the formulation of monetary policy. For this loss function, the coefficient of relative prudence [see Kimball (1990)] is $\gamma\left(\pi_{t}-\pi^{*}\right)$, that is directly proportional to the inflation deviation from its target and increasing in $\gamma$. Finally, it nests the quadratic function commonly used in previous literature as a special case when 
the preference parameter $\gamma$ tends to zero. ${ }^{1}$ This result is important because it suggests that the hypothesis that the central banker's preferences are quadratic over inflation could be evaluated by testing whether $\gamma$ is statistically different from zero.

The central bank takes as given the behavior of the private sector, that is summarized by:

$$
\begin{aligned}
& y_{t+1}=\delta y_{t}-r_{t}+\eta x_{t}, \\
& \pi_{t+1}=\pi_{t}+f\left(y_{t}\right)+u_{t+1},
\end{aligned}
$$

where

$$
\begin{aligned}
f\left(y_{t}\right) & =\alpha y_{t} /\left(1-\alpha \phi y_{t}\right), \\
x_{t+1} & =\psi x_{t}+e_{t+1}, \\
i_{t} & =r_{t}+E_{t} \pi_{t+1},
\end{aligned}
$$

$y_{t}$ is the output gap, $r_{t}$ is the real interest rate, $x_{t}$ is an exogenous variable that follows the $\mathrm{AR}(1)$ process in (5), $u_{t}$ and $e_{t}$ are normally and independently distributed shocks with zero mean and variances $\sigma_{u}^{2}$ and $\sigma_{e}^{2}$, respectively, and the remaining parameters satisfy $0<$ $\psi, \delta<1, \alpha>0$, and $\phi \geq 0$. Note that although we assume constant unconditional variances for $u_{t}$ and $e_{t}$, we allow the possibility that these shocks are conditionally heteroskedastic. Equation (2) is an IS relationship where the output gap depends on the lagged output gap, the real interest rate, and the exogenous variable, $x_{t}$. Equation (3) is a backward-looking AS relationship where inflation depends on lagged inflation and output gap, the latter appearing in a (possibly) non-linear way. The nonlinearity of the AS curve is represented using the functional form (4). This form is more tractable than other specifications used in the literature [see, for example, Nobay and Peel (2000)] and includes the cases of a linear AS curve when $\phi=0$ and a convex one when $\phi>0$. Finally, equation (6) is the Fisher relation. Although this model is a highly stylized description of the economy, it is representative of the type of models used by the literature on monetary policy rules.

Since the interest rate affects inflation with a two-period lag, without any effects in $t$ and $t+1$, the central bank can find the optimal interest rate at time $t$ as the solution to the simpler period-by-period problem [see Svensson (1997)]:

$$
\begin{aligned}
& \operatorname{Min} E_{t} \beta^{2} L\left(\pi_{t+2}-\pi^{*}\right) . \\
& \left\{i_{t}\right\}
\end{aligned}
$$

\footnotetext{
${ }^{1}$ Formally,

$$
\operatorname{Lim}_{\gamma \rightarrow 0} \frac{\exp (\gamma x)-\gamma x-1}{\gamma^{2}}=\operatorname{Lim}_{\gamma \rightarrow 0} \frac{x \exp (\gamma x)-x}{2 \gamma}=\operatorname{Lim}_{\gamma \rightarrow 0} \frac{x^{2} \exp (\gamma x)}{2}=\frac{x^{2}}{2} .
$$
}


The Appendix shows that the first-order conditions for minimizing (7) subject to the constraints (2) and (3), yields the following Taylor rule for the nominal interest rate:

$$
i_{t}=\pi_{t}+f\left(y_{t}\right)+\delta y_{t}+\frac{(1 / \alpha)\left(\pi_{t}-\pi^{*}+\gamma \sigma_{\pi, t}^{2} / 2+f\left(y_{t}\right)\right)}{1-\phi\left(\pi_{t}-\pi^{*}+\gamma \sigma_{\pi, t}^{2} / 2+f\left(y_{t}\right)\right)}+\eta x_{t}
$$

where $\sigma_{\pi, t}^{2}=\sigma_{u, t}^{2}$ denotes the conditional variance of the inflation rate.

A key assumption of the model is that the central bank's loss function excludes an output stabilization term. The reason for this exclusion is analytical tractability. The Appendix shows that when an output term is allowed for in the loss function, it is not possible to obtain a closed-form solution for the central bank's problem and, consequently, the Taylor rule cannot be characterized analytically. Svensson (1997) shows that allowing an output stabilization term in a linear model does not change the form of the policy function compared with the case of pure inflation targeting, but the response of the interest rate target to inflation and output gaps is more gradual.

The Taylor rule (8) is general in that it nests the cases where the central bank's preferences are quadratic $(\gamma \rightarrow 0)$, the AS schedule is linear $(\phi=0)$, or both. The latter case corresponds to the linear monetary policy rules examined by previous literature. In order to gain intuition regarding this policy rule, the following sections examine three special cases contained in (8).

\subsection{Case I: Linear Aggregate Supply Schedule $(\phi=0)$}

When $\phi=0$, the function $f(\cdot)$ becomes $f\left(y_{t}\right)=\alpha y_{t}$ and the AS curve is linear. In this case the only nonstandard feature of the model is the asymmetry in central bank preferences, and the nonlinear Taylor rule simplifies to

$$
i_{t}=\pi_{t}+(1+\alpha+\delta) y_{t}+(1 / \alpha)\left(\pi_{t}-\pi^{*}+\gamma \sigma_{\pi, t}^{2} / 2\right)+\eta x_{t} .
$$

Under asymmetric preferences, the conditional variance of inflation, $\sigma_{\pi, t}^{2}$ (along with the inflation rate and the output gap) is one of the main determinants of the interest rate target. Up to the extent that $\sigma_{\pi, t}^{2}$ depends on lagged inflation and output (for example, as in ARCHtype models), the Taylor rule is nonlinear on lagged inflation and output.

Consider the situation where $\gamma>0$, meaning that the central bank weights more severely positive than negative inflation deviations from its optimal rate. Since $\alpha>0$, an increase in inflation volatility (as measured by $\sigma_{\pi, t}^{2}$ ), leads to an increase in the nominal interest rate, even if the level of inflation and the output gap remain unchanged. The increase is directly proportional to $\gamma$ because the central bank's prudence increases with $\gamma \cdot{ }^{2}$ The increase is

\footnotetext{
${ }^{2} \mathrm{~A}$ comparable result can be found in the literature on precautionary savings. When the assumption of
} 
inversely proportional to $\alpha$ for the following reason: when $\alpha$ is large, the central bank needs to increase the nominal and real interest rates by less because a given decrease in the output gap leads to a proportionally larger decrease in inflation when the AS curve is steep.

\subsection{Case II: Quadratic Loss Function $(\gamma \rightarrow 0)$}

When $\gamma \rightarrow 0$, the central bank preferences become quadratic on inflation and there is no longer a prudence motive in the implementation of monetary policy. However, if $\phi>0$, the AS curve is convex and the Taylor rule takes the nonlinear form

$$
i_{t}=\pi_{t}+f\left(y_{t}\right)+\delta y_{t}+\frac{(1 / \alpha)\left(\pi_{t}-\pi^{*}+f\left(y_{t}\right)\right)}{1-\phi\left(\pi_{t}-\pi^{*}+f\left(y_{t}\right)\right)}+\eta x_{t} .
$$

In this case $y_{t}$, will not appear in a linear way but through the $f(\cdot)$ transformation. As a result of the second-to-last term in (10), the nominal interest rate will depend nonlinearly on inflation and the output gap, but this nonlinearity is conceptually and functionally different from the one in Case I above. It is shown below that when the AS curve is convex, interest rate changes in response to inflation/output deviations from their target are subject to sign and size asymmetries.

\subsection{Case III: Linear Rule}

The case where both $\gamma \rightarrow 0$ and $\phi=0$ corresponds to the usual model with quadratic preferences and linear constraints. In this case, the optimal reaction function is linear in inflation and output:

$$
i_{t}=\pi_{t}+(1+\alpha+\delta) y_{t}+(1 / \alpha)\left(\pi_{t}-\pi^{*}\right)+\eta x_{t}
$$

We will see below, in this case changes in the short-term nominal interest rate are symmetric, proportional, and history-independent. Put differently, for linear models, the impulseresponse associated with a shock of size 1 (standard deviation) would be the mirror image of the response to a shock of size -1 , one-half the response of shock size 2 , and independent of the moment the shock is assumed to take place [see Gallant, Rossi, and Tauchen (1993) and Koop, Pesaran, and Potter (1996)].

quadratic utility is relaxed and labor-income risk in nondiversifiable, then uncertainty increases the expected marginal utility of future consumption. To satisfy the Euler condition, prudent households decrease current consumption compared to future consumption and increase their savings. 


\subsection{Implications}

As we have seen above, the combination of asymmetric central bank preferences and a nonlinear AS curve has nontrivial implications for the interest-rate response to inflation and output gap deviations from their desired values. This section explores in more detail some of these implications and the interaction between the two main features of the model.

When the AS curve is linear, a marginal change in the current inflation rate leads the central bank to change the nominal interest rate by $\partial i_{t} / \partial \pi_{t}=1+1 / \alpha$. In this case, the change in $i_{t}$ is independent of the current output gap and inflation rate and is symmetric, meaning that if inflation increases (decreases) by 1 percent, the nominal interest rate increases (decreases) by $1+1 / \alpha$ percent.

In contrast, under the general Taylor rule (8) (where the AS curve is nonlinear), the change in $i_{t}$ is $\partial i_{t} / \partial \pi_{t}=1+(1 / \alpha)\left(1-\phi\left(\pi_{t}-\pi^{*}+\gamma \sigma_{\pi, t}^{2} / 2+f\left(y_{t}\right)\right)^{-2}\right.$. The nonlinear interest rate rule gives rise to sign and size asymmetries. The sign asymmetry refers to the fact that under the nonlinear Taylor rule, the response to an increase in inflation is larger than the response to a decrease, even if both are of the same magnitude. As an illustration, assume that inflation is exactly the optimal rate, the output gap is zero, and $\alpha=2, \delta=0.1, \phi=0.2$ and $\gamma \sigma_{\pi, t}^{2} / 2=0.4$. Then, $\Delta \pi_{t}=+1$ induces $\Delta i_{t}=+1.76$ but $\Delta \pi_{t}=-1$ induces $\Delta i_{t}=-1.48$.

The size asymmetry refers to the fact that the interest rate response does not change linearly with the change in the inflation rate. For example, taking the same parameter values above, $\Delta \pi_{t}=+1$ induces $\Delta i_{t}=+1.76$ but $\Delta \pi_{t}=+2$ induces $\Delta i_{t}=+4.09$. Although $\Delta \pi_{t}=+2$ is twice $\Delta \pi_{t}=+1$, the interest rate response +4.09 is more than twice +1.76 . On the other hand, while $\Delta \pi_{t}=-1$ induces $\Delta i_{t}=-1.48, \Delta \pi_{t}=-2$ induces $\Delta i_{t}=-2.82$, that is less than twice -1.48 . The sign and size asymmetries that arise when the AS curve is convex follow directly from the fact that the interest rate response with respect to inflation $\left(\partial i_{t} / \partial \pi_{t}\right)$ is convex on the rate of inflation.

Note that when $\gamma=0$ and, consequently, $\gamma \sigma_{\pi, t}^{2} / 2=0$, the corresponding interest rate responses to $\Delta \pi_{t}=+1$ and -1 under the nonlinear Taylor rule would be $\Delta i_{t}=+1.63$ and -1.42 , respectively, whereas for $\Delta \pi_{t}= \pm 2$ they would be $\Delta i_{t}=+3.67$ and -2.71 . Hence, asymmetric preferences appear to reduce the size of both the sign and size asymmetries. The reason is that the interest rate response to inflation is less convex on inflation as $\gamma \sigma_{\pi, t}^{2} / 2$ decreases.

Similar results regarding sign and size asymmetries arise when considering the interest rate response to a change in the output gap. When the AS curve is linear, $\partial i_{t} / \partial y_{t}=1+\alpha+\delta$, but under the nonlinear Taylor rule, $\partial i_{t} / \partial y_{t}=\delta+f^{\prime}\left(y_{t}\right)\left(1+\left(1-\phi\left(\pi_{t}-\pi^{*}+\gamma \sigma_{\pi, t}^{2} / 2+f\left(y_{t}\right)\right)^{-2}\right)\right.$ 
where $f^{\prime}\left(y_{t}\right)=\partial f\left(y_{t}\right) / \partial y_{t}=\alpha\left(1-\alpha \phi y_{t}\right)^{-2}$. The interest rate depends nonlinearly on the current output gap giving rise to asymmetric responses on the part of the central bank. For the parameter values above, the interest rate response to $\Delta y_{t}= \pm 0.1$ is $\Delta i_{t}=0.35$ and -0.31 . The response to $\Delta y_{t}= \pm 0.2$ is 0.74 and -0.59 . Hence, as before, the response depends on the sign of the output gap deviation from its target and is nonlinearly related to the size of the deviation.

In summary, a convex AS curve leads an optimizing central bank to respond asymmetrically, in both sign and size, to changes in the output gap and inflation rate. Asymmetric

preferences leads to prudent behavior whereby the central bank responds to the conditional variance of inflation. When the conditional variance of inflation is well approximated by an ARCH-type process, the central bank responds nonlinearly to lagged inflation and output. When both features are present, asymmetric preferences appear to reduce the sign and size asymmetries that arise due to the nonlinearity of the supply curve. Since asymmetric preferences and a nonlinear AS schedule lead to different types of nonlinearity in the interest rate response by the central bank, it might be possible to assess empirically relative importance of these two elements in monetary policy making.

\section{Empirical Evidence}

\subsection{The Data}

The nonlinear Taylor rule is estimated using US data on inflation, the output gap, and the federal funds rate. Previous literature employs both monthly and quarterly data frequencies to estimate monetary policy rules. We report results using both data frequencies and show that the main result of the paper is robust to whether one uses monthly or quarterly data in estimation. At the monthly frequency, inflation is measured by the annual percentage change in the Consumer Price Index (CPI). Output is measured by the seasonally-adjusted Industrial Production Index (IPI). The natural output level is the Hodrick-Prescott (HP) trend of the logged IPI. The output gap is then computed as the difference between the logged IPI and its HP trend. We also consider a second measure of the output gap constructed as minus the difference between the seasonally-adjusted unemployment rate and its HP trend. The sample period is 1970:01 to 2000:12, but we focus on the subsamples 1970:01 to 1979:06 and 1983:01 to 2000:12. The first subsample corresponds (roughly) to the chairmanships of Arthur Burns and William Miller. The second subsample corresponds to the chairmanships of Paul Volcker and Alan Greenspan, but excludes the period when the Federal Reserve targeted nonborrowed reserves, rather than short-term interest rates. 
At the quarterly frequency, inflation is measured by the annualized quarterly percentage change in the Implicit GDP Deflator. Two measures of the output gap are constructed as explained above, except that the quarterly observation of the IPI and unemployment rate is the arithmetic average of the three observations in each quarter. Since at the quarterly frequency the number of observations in the first subsample 1970:I to 1979:II is too small to yield reliable results, we follow Clarida et al. (2000) in starting the quarterly sample in 1960:I.

In the econometric analysis below, we assume that the model variables are stationary in levels. Although unit-root test results do not always support this assumption for all variables and frequencies, it is well known that unit-root tests have low power and are biased in favor of the null when there are changes in regime as the ones documented by this paper.

\subsection{Preliminary Analysis}

The estimation of the non-linear Taylor-rule is carried out using a two-step procedure. First, the conditional variance of inflation is estimated from the aggregate supply relation. Then, $\sigma_{\pi, t}^{2}$ is replaced in the Taylor rule and the rule is estimated by Generalized Method of Moments (GMM). However, some issues need to be addressed prior to estimation. First, the precise form of the non-linear Taylor rule depends on whether the aggregate supply relation is linear or not. Recall that the AS curve is linear when $\phi=0$ and convex when $\phi>0$. Hence, it is important to test whether $\phi$ is statistically different from zero in our data set. Second, the prediction that the conditional variance of inflation is a component of the policy rule can be examined in a time series setup only if inflation is conditionally heteroskedastic. That is, if $\sigma_{\pi, t}^{2}$ varies over time. Otherwise, if $\sigma_{\pi, t}^{2}$ is constant, its coefficient might not be identified. Hence, one must also test whether the conditional variance of inflation is indeed time-varying.

In order to address these two issues, we estimate the aggregate supply relation (3) by nonlinear least squares under the assumption that the disturbance term $u_{t}$ is conditionally homoskedastic. We then test the null hypothesis $\phi=0$ using a $t$-test, and the null hypothesis of no conditional heteroskedasticity using a LM test for neglected ARCH. The LM statistics were calculated as the product of the number of observations and the uncentered $R^{2}$ of the OLS regression of the squared unemployment residual on a constant and six of its lags. Under the null hypothesis of no conditional heteroskedasticity, the statistic is distributed chisquare with as many degrees of freedom as the number of lagged squared residuals included in the regression.

Results in Panels A and B of Table 1, support the notion of an upward sloping AS curve 
(as predicted by the theory), but results using quarterly data are somewhat weaker than the ones using monthly data. This result might be explained by the fact that the econometrician has more data points to estimate $\alpha$ when using monthly than quarterly data. In all cases the hypothesis $\phi=0$ cannot be rejected at standard levels. Hence, for these sample periods and data frequencies, it would appear that the US aggregate supply curve is well approximated by a linear relation. Results of the LM tests for neglected $\mathrm{ARCH}$ are reported in the first row of Table 2. Note that the hypothesis of no conditional heteroskedasticity is rejected for both frequencies and output gap measures.

In light of these results, we estimate a linear (in mean) AS curve with conditionally heteroskedastic errors. The parameter $\phi$ is constrained to be zero and the conditional variance of inflation is parameterized using a $\operatorname{GARCH}(1,1)$ model. These results are reported in Panel C of Table 1. The terms $\psi_{0}, \psi_{1}$, and $\psi_{2}$ denote the constant, the coefficient of the lagged square residual, and the coefficient of the lagged conditional variance, respectively. Note that in all cases their estimates are significant and suggest a persistent process for $\sigma_{\pi, t}^{2}$.

Since the conditional variance is estimated using inflation and output data, $\sigma_{\pi, t}^{2}$ is a generated regressor for the second step of the estimation procedure. The implications of generated regressors in estimation and inference have been examined by Pagan (1984) and Pagan and Ullah (1988). Generated regressors can be problematic because they measure with noise the true, but unobserved, regressor. In the case of models where a conditional variance is one of the explanatory variables, estimates can be biased and inconsistent if the ARCH-type model employed is misspecified. Pagan and Ullah (p. 99) suggest specification tests to assess whether the chosen $\mathrm{ARCH}$ model is valid. A standard misspecification test for $\mathrm{ARCH}$ models is the same LM test for neglected $\mathrm{ARCH}$ described above, but applied to the standardized residuals. If the $\mathrm{ARCH}$ model is correctly specified, then the residuals corrected for heteroskedasticity and squared should be serially uncorrelated. The second row in Table 2 reports these LM statistics. Since all statistics are below the 5 percent critical value of the appropriate distribution, the null hypothesis of no autocorrelation cannot be rejected. Hence, it would appear that the parsimonious $\operatorname{GARCH}(1,1)$ model employed here adequately captures the conditional heteroskedasticity present in the US inflation data.

\subsection{Estimation}

As is customary in the empirical literature on monetary policy rules, the observed smoothing of interest rates is captured by a partial adjustment model whereby lagged values of the interest rate are also included as explanatory variables. The optimally determined interest rate is interpreted as the desired rate towards which the current interest rate sluggishly 
adjusts. That is,

$$
i_{t}=\rho(L) i_{t-1}+(1-\rho) i_{t}^{*}+\xi_{t}
$$

where $\rho(L)=\rho_{1}+\rho_{2} L+\cdots+\rho_{n+1} L^{n}, \rho \equiv \rho(1)$, and $i_{t}^{*}$ is given by the right hand side of equation (9). Substituting (9) into (12), the estimated model is

$$
i_{t}=a+\rho(L) i_{t-1}+(1-\rho)\left(b y_{t}+c \pi_{t}+d \sigma_{\pi, t}^{2}+\eta x_{t}\right)+\xi_{t},
$$

where $a$ is an intercept term, $b=1+1 / \alpha, c=1+\alpha+\delta$, and $d=\gamma / 2 \alpha$.

If the current values of inflation and the output gap are taken to be unknown by the central bank when setting interest rates, then equation (13) can be estimated by Instrumental Variables (IV), using lagged values of the variables as instruments. As an additional check on the robustness of the results, we also estimate two forward-looking versions of (13) where the current values of $\pi_{t}\left(y_{t}\right)$ are replaced by expectations of future variables $k(q)$ periods ahead, $E_{t} \pi_{t+k}$ and $E_{t} y_{t+q}$, and a backward-looking version where they are replaced by $\pi_{t-1}\left(y_{t-1}\right)$.

The partial adjustment models were estimated by Generalized Method of Moments (GMM). ${ }^{3}$ Denoting by $\mathbf{z}_{t}$ a vector of $m$ instruments, GMM exploits the set of orthogonality conditions $E\left(\xi_{t} \mid \mathbf{z}_{t}\right)=0$ to estimate the relevant parameters. The validity of the $(m-p)$ overidentification restrictions can be assessed through the $J$ test that is asymptotically distributed as a chi-square with $(m-p)$ degrees of freedom.

The estimated nonlinear rules are reported in Tables 3 and 4, for the periods 1970:01 to 1979:06 and 1983:01 to 2000:12, respectively. The basic difference between both set of results is that the coefficient on the conditional variance of inflation $(d)$ is not statistically significant in the first subsample, but it is always positive and significant in the second one. This result is robust to both forward and backward-looking specifications of the Taylor rule [see columns (3) to (5)]. Notice that in most cases for the second subsample, the rate of inflation is no longer statistically significant once one introduces the conditional variance as a regressor. ${ }^{4}$ In all cases, the overidentification restrictions of the model are not rejected by the data at standard significant levels.

These findings suggest the following. First, monetary policy in the United States could be well approximated by a linear Taylor rule prior to 1979. Second, the Fed's inflation preferences could be described as symmetric with respect to inflation in the period prior 1979. More precisely, the hypothesis that preferences are quadratic $(\gamma=0)$ would not

\footnotetext{
${ }^{3}$ In the case of forward-looking rules, we replace expectations of future variables by their realized values. Then, by construction, the error term in the estimable form will be a $M A(h)$ process with $h=\max \{k, q\}-1$ implying that an optimal weighting matrix that allows for serial correlation ought to be used.

${ }^{4}$ Note that the conditional variance employed here is the one estimated using the full sample. However, using estimates of $\sigma_{\pi, t}^{2}$ for each subperiod yields qualitatively the same results as those reported.
} 
be rejected by the data against the alternative of asymmetric preferences $(\gamma \neq 0)$. Third, after 1983, a nonlinear Taylor rule seems to provide a more accurate characterization of US monetary policy than a linear rule. In particular, the Federal Funds rate appears to react more strongly to the volatility than to the level of inflation after 1983. Fourth, since the coefficient on the conditional variance of inflation is positive and statistically significant after 1983, this suggest that the Fed's inflation preferences during the Volcker-Greenspan might be asymmetric. In particular, positive deviations of inflation from its target appear to be weighted more severely than negative ones, even if they are of the same magnitude.

\subsection{Comparison with Clarida, Gali, and Gertler (2000)}

The results above parallel somewhat the evidence in Clarida et al. (2000), where it is reported that the coefficient on inflation in a forward-looking version of the Taylor rule is substantially different in the pre-Volcker and Volcker-Greenspan eras. In order to make this comparison more direct, consider results in Tables 5 and 6 that report the estimated rules using quarterly data for the periods 1960:I to 1979:II and 1983:I to 2000:IV. As before, the second sample excludes the period when the Federal Reserve targeted nonborrowed reserves, rather than short-term interest rates. However, starting the second subsample in 1979:III yields the same results as reported here. ${ }^{5}$

Column (1) in both tables illustrates Clarida et al.'s main result, namely that the reaction with respect to inflation $(c)$, is smaller than unity prior to 1979 but larger than unity during the tenure of chairmen Volcker and Greenspan. This result is robust to the measure of the output gap. However, note in Table 5 that this result does not hold completely once we allow for asymmetric inflation preferences on the part of the central bank. Although results are sensitive to the form of the rule, there are specifications for which the point estimate of $c$ is larger than one prior to 1979, though one would not be able to reject the null hypothesis that the true value is less than one. For example, column (3) in Table 5 correspond to the baseline model reported by Clarida et al. (p. 157) but includes the conditional variance of inflation as one of the regressors. The point estimates of the inflation coefficient are $1.14(0.12)$ and 1.04(0.12) depending on the output gap measure employed. Also, notice that in certain cases, the coefficient on $\sigma_{\pi}^{2}$ is negative and statistically different from zero. The intuition for this result is explained below.

Regarding the post-1982 data, Table 6 shows that the inflation response is considerably smaller when we allow asymmetric preferences. For some specifications, $\hat{c}$ is smaller than

\footnotetext{
${ }^{5}$ Results when the second subsample is 1979:III to 2000:IV are available from the corresponding author upon request.
} 
one, though one would not be able to reject the null hypothesis that the true value is larger than one. The reason for this result is straightforward: since the conditional variance of inflation depends on lagged squared inflation, the inflation response consists of a linear part, with coefficient $c$, and a nonlinear part, with coefficient $d$. The overall response with respect to inflation is most likely stabilizing, as suggested by Clarida et al. The contribution of Table 6 is to show that the nonlinear reaction to the conditional variance of inflation is a quantitative and, in most cases, statistically important component of Fed's reaction function after 1982 .

\subsection{What Drives the Results?}

In order to understand the empirical results reported in this paper, it is instructive to consider the relation between the real interest rate and the conditional variance of inflation in both subsamples. Although the policy rule is defined in terms of the nominal interest rate, one can think of the central bank as implicitly targeting a measure of the real interest rate, that in turn affects output through the IS curve. Figures 1 and 2 plot the relation between the two variables at the quarterly frequency, and the fitted values of an OLS regression of the real rate on $\sigma_{\pi}^{2}$. The estimated parameters of these regressions are reported in columns (3) and (4) in Table 7. (Results using monthly data are reported in columns (1) and (2).) Notice that in the first subsample, the real rate is negatively but mildly related to the conditional variance. The coefficient is statistically different from zero, but given the large variability of inflation during this period, the real interest rate response is considerably muted. In contrast, in the second subsample, there is a strong positive relationship between the two variables. The result is striking in that inflation is much less volatile in the second than in the first subsample. The positive relation between the real interest rate and the conditional variance of inflation is consistent with asymmetric inflation preferences because this specification predicts a prudence motive in the implementation of monetary policy.

\section{Conclusions}

This paper contributes to the literature on optimal monetary policy rules by considering setups where certainty equivalence does not hold because either central bank preferences are not quadratic and/or the aggregate supply schedule is convex. Under some simplifying assumptions, albeit not restrictive ones, it is possible to derive a nonlinear Taylor rule incorporating both features. This rules is general in that it nests the cases where either feature is present or where none is and, consequently, the monetary policy rule is linear. 
In order to examine how relevant nonlinear monetary policy rules are in practice, we estimate the rule using US data during the Burns-Miller (pre-1979) and Volcker-Greenspan (post-1982) regimes at the US Federal Reserve. Although, there is no evidence against a linear aggregate supply schedule in either regime, we find fairly robust evidence in favor of the view that the central bank preferences are considerably different in both regimes. In particular, the Fed's inflation preferences during the Volcker-Greenspan regime appear to be asymmetric, in the sense that positive inflation deviations from its target are weighted more heavily than negative ones, even if they are of the same magnitude. In contrast, it is not possible to reject the null hypothesis of quadratic inflation preferences during the BurnsMiller regime. Under asymmetric preferences, the fact that certainty equivalence does not hold, means that a prudence motive can arise in the conduct of monetary policy and interest rates respond not only to inflation changes but also to its variability.

A final interesting result of this paper is that, in contrast to Clarida et al. (2000) who report that interest rate policy in the Volcker-Greenspan period appears to have been much more sensitive to changes in expected inflation than in the pre-Volcker period, we do not find the response of interest rates to inflation to be larger than unity in the Volcker-Greenspan period. However, once the additional effect stemming from the conditional variance of inflation is considered, the rule in the Volcker-Greenspan era is found to be stabilizing as well. 
Table 1. Estimated Aggregate Supply Schedules

\begin{tabular}{|c|c|c|c|c|}
\hline \multirow[b]{2}{*}{ Coefficients } & \multicolumn{2}{|c|}{ Monthly Data } & \multicolumn{2}{|c|}{ Q Quarterly Data } \\
\hline & $\begin{array}{l}\mathrm{IPI} \\
(1) \\
\end{array}$ & $\begin{array}{c}(-) \text { Unemp. } \\
(2)\end{array}$ & $\begin{array}{l}\text { IPI } \\
(3) \\
\end{array}$ & $\begin{array}{c}(-) \text { Unemp. } \\
(4)\end{array}$ \\
\hline \multicolumn{5}{|c|}{ Panel A. Linear } \\
\hline$\hat{\alpha}$ & $\begin{array}{c}0.06^{*} \\
(0.006)\end{array}$ & $\begin{array}{l}0.24^{*} \\
(0.03)\end{array}$ & $\begin{array}{c}0.05^{\dagger} \\
(0.029)\end{array}$ & $\begin{array}{c}0.21^{\dagger} \\
(0.13)\end{array}$ \\
\hline \multicolumn{5}{|c|}{ Panel B. Nonlinear with No ARCH } \\
\hline$\hat{\alpha}$ & $\begin{array}{c}0.06^{*} \\
(0.007)\end{array}$ & $\begin{array}{l}0.24^{*} \\
(0.03)\end{array}$ & $\begin{array}{c}0.04 \\
(0.03)\end{array}$ & $\begin{array}{c}0.06 \\
(0.05)\end{array}$ \\
\hline$\widehat{\phi}$ & $\begin{array}{c}0.31 \\
(0.47)\end{array}$ & $\begin{array}{c}0.12 \\
(0.59)\end{array}$ & $\begin{array}{l}-0.79 \\
(2.47)\end{array}$ & $\begin{array}{c}47.92 \\
(37.87)\end{array}$ \\
\hline \multicolumn{5}{|c|}{ Panel C. Linear with $G A R C H(1,1)$} \\
\hline$\hat{\alpha}$ & $\begin{array}{c}0.05^{*} \\
(0.006)\end{array}$ & $\begin{array}{l}0.22^{*} \\
(0.03)\end{array}$ & $\begin{array}{l}0.015 \\
(0.03)\end{array}$ & $\begin{array}{c}0.08 \\
(0.15)\end{array}$ \\
\hline$\widehat{\phi}$ & 0 & 0 & 0 & 0 \\
\hline & - & - & - & - \\
\hline$\widehat{\psi}_{0}$ & $\begin{array}{c}0.005^{*} \\
(0.0025)\end{array}$ & $\begin{array}{c}0.004^{*} \\
(0.0019)\end{array}$ & $\begin{array}{c}0.07^{\dagger} \\
(0.04)\end{array}$ & $\begin{array}{c}0.07^{\dagger} \\
(0.04)\end{array}$ \\
\hline$\widehat{\psi}_{1}$ & $\begin{array}{l}0.21^{*} \\
(0.05)\end{array}$ & $\begin{array}{l}0.17^{*} \\
(0.05)\end{array}$ & $\begin{array}{c}0.08^{\dagger} \\
(0.05)\end{array}$ & $\begin{array}{l}0.08^{\dagger} \\
(0.05)\end{array}$ \\
\hline$\widehat{\psi}_{2}$ & $\begin{array}{l}0.75^{*} \\
(0.06)\end{array}$ & $\begin{array}{c}0.80^{*} \\
0.05\end{array}$ & $\begin{array}{l}0.87^{*} \\
(0.06)\end{array}$ & $\begin{array}{c}0.87^{*} \\
(0.06)\end{array}$ \\
\hline
\end{tabular}

Notes: The figures in parenthesis are standard errors. The superscripts ${ }^{*}$ and ${ }^{\dagger}$ denote the rejection of the hypothesis that the true coefficient is zero at the 5 percent and 10 percent significance levels, respectively. 
Table 2. LM Test for Neglected ARCH

\begin{tabular}{|c|c|c|c|c|}
\hline \multirow[b]{2}{*}{ Residuals } & \multicolumn{2}{|c|}{ Monthly Data } & \multicolumn{2}{|c|}{ 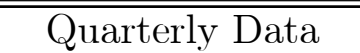 } \\
\hline & $\begin{array}{l}\text { IPI } \\
\text { (1) }\end{array}$ & $\begin{array}{c}\text { (-)Unemp. } \\
(2)\end{array}$ & $\begin{array}{l}\text { IPI } \\
(3)\end{array}$ & $\begin{array}{c}\text { (-)Unemp. } \\
\text { (4) }\end{array}$ \\
\hline Original & $34.54^{*}$ & $25.96^{*}$ & $15.72^{*}$ & $24.29^{*}$ \\
\hline Standardized & 4.50 & 3.34 & 9.83 & 9.93 \\
\hline
\end{tabular}

Notes: The LM statistics were calculated as the product of the number of observations and the uncentered $R^{2}$ of the OLS regression of the squared unemployment residual on a constant and six of its lags. The superscripts ${ }^{*}$ and ${ }^{\dagger}$ denote the rejection of the null hypothesis of conditional homoskedasticity at the 5 percent and 10 percent significance levels, respectively. 
Table 3. Estimated Reaction Functions

Monthly Data

Pre-Volcker

\begin{tabular}{|c|c|c|c|c|c|}
\hline \multirow[b]{3}{*}{ Coefficient } & \multicolumn{5}{|c|}{ Nonlinear } \\
\hline & \multirow[b]{2}{*}{$\begin{array}{l}\text { Linear } \\
(1)\end{array}$} & \multicolumn{3}{|c|}{ Forward $(q, k)$} & \multirow[b]{2}{*}{$\begin{array}{c}\text { Backward } \\
(5)\end{array}$} \\
\hline & & $\begin{array}{l}\text { Baseline } \\
\text { (2) }\end{array}$ & $\begin{array}{c}(3,6) \\
(3)\end{array}$ & $\begin{array}{c}(6,6) \\
(4)\end{array}$ & \\
\hline \multicolumn{6}{|c|}{ Panel A. Using IPI Gap } \\
\hline$\hat{a}$ & $\begin{array}{l}-0.10 \\
(0.33)\end{array}$ & $\begin{array}{l}0.38^{*} \\
(0.15)\end{array}$ & $\begin{array}{l}0.39^{*} \\
(0.08)\end{array}$ & $\begin{array}{l}0.32^{*} \\
(0.09)\end{array}$ & $\begin{array}{l}0.36^{*} \\
(0.17)\end{array}$ \\
\hline$\hat{b}$ & $\begin{array}{l}0.57^{\dagger} \\
(0.31)\end{array}$ & $\begin{array}{l}0.49^{*} \\
(0.13)\end{array}$ & $\begin{array}{c}0.08 \\
(0.06)\end{array}$ & $\begin{array}{l}0.12^{\dagger} \\
(0.11)\end{array}$ & $\begin{array}{l}0.43^{*} \\
(0.10)\end{array}$ \\
\hline$\hat{c}$ & $\begin{array}{l}0.84^{*} \\
(0.31)\end{array}$ & $\begin{array}{l}0.38^{\dagger} \\
(0.22)\end{array}$ & $\begin{array}{l}0.73^{*} \\
(0.07)\end{array}$ & $\begin{array}{l}0.80^{*} \\
(0.09)\end{array}$ & $\begin{array}{l}0.40^{\dagger} \\
(0.23)\end{array}$ \\
\hline$\hat{d}$ & $\begin{array}{l}0 \\
-\end{array}$ & $\begin{array}{c}4.27 \\
(6.81)\end{array}$ & $\begin{array}{l}-5.19 \\
(3.57)\end{array}$ & $\begin{array}{l}-5.94 \\
(4.31)\end{array}$ & $\begin{array}{c}4.52 \\
(7.41)\end{array}$ \\
\hline$J$ statistic & 4.98 & 6.76 & 6.20 & 7.15 & 7.14 \\
\hline d.f. & 8 & 13 & 13 & 13 & 13 \\
\hline \multicolumn{6}{|c|}{ Panel B. Using (minus) Unemployment Gap } \\
\hline$\hat{a}$ & $\begin{array}{c}0.34 \\
(0.28)\end{array}$ & $\begin{array}{l}0.71^{*} \\
(0.17)\end{array}$ & $\begin{array}{l}0.78^{*} \\
(0.16)\end{array}$ & $\begin{array}{c}0.80^{*} \\
(0.16)\end{array}$ & $\begin{array}{c}0.27 \\
(0.22)\end{array}$ \\
\hline$\hat{b}$ & $\begin{array}{l}1.93^{*} \\
(0.50)\end{array}$ & $\begin{array}{l}4.33^{*} \\
(1.30)\end{array}$ & $\begin{array}{l}0.29^{*} \\
(0.14)\end{array}$ & $\begin{array}{l}0.37^{*} \\
(0.17)\end{array}$ & $\begin{array}{l}2.04^{*} \\
(0.33)\end{array}$ \\
\hline$\hat{c}$ & $\begin{array}{l}0.75^{*} \\
(0.13)\end{array}$ & $\begin{array}{c}0.10 \\
(0.29)\end{array}$ & $\begin{array}{l}0.70^{*} \\
(0.04)\end{array}$ & $\begin{array}{c}0.70^{*} \\
(0.04)\end{array}$ & $\begin{array}{l}0.72^{*} \\
(0.10)\end{array}$ \\
\hline$\hat{d}$ & - & $\begin{array}{c}3.03 \\
(4.92)\end{array}$ & $\begin{array}{l}-3.35 \\
(2.05)\end{array}$ & $\begin{array}{c}-3.93^{\dagger} \\
(2.05)\end{array}$ & $\begin{array}{c}4.02 \\
(5.09)\end{array}$ \\
\hline$J$ statistic & 7.02 & 6.43 & 6.63 & 6.17 & 7.93 \\
\hline d.f. & 8 & 13 & 13 & 13 & 13 \\
\hline
\end{tabular}

Notes: The figures in parenthesis are standard errors. The instruments are a constant and six lags of the variables in the estimated rule. d.f. stands for degrees of freedom. The superscripts ${ }^{*}$ and ${ }^{\dagger}$ denote the rejection of the hypothesis that the true coefficient is zero at the 5 percent and 10 percent significance levels, respectively. 
Table 4. Estimated Reaction Functions

Monthly Data

Volcker-Greenspan

\begin{tabular}{|c|c|c|c|c|c|}
\hline \multirow[b]{3}{*}{ Coefficient } & \multirow[b]{3}{*}{$\begin{array}{l}\text { Linear } \\
(1)\end{array}$} & \multicolumn{3}{|c|}{ Nonlinear } & \multirow[b]{3}{*}{$\begin{array}{c}\text { Backward } \\
(5)\end{array}$} \\
\hline & & & Forwa & $\mathrm{d}(q, k)$ & \\
\hline & & $\begin{array}{c}\text { Baseline } \\
\text { (2) }\end{array}$ & $\begin{array}{c}(3,6) \\
(3)\end{array}$ & $\begin{array}{c}(6,6) \\
(4)\end{array}$ & \\
\hline \multicolumn{6}{|c|}{ Panel A. Using IPI Gap } \\
\hline$\hat{a}$ & $\begin{array}{l}0.50^{*} \\
(0.23)\end{array}$ & $\begin{array}{l}0.38^{*} \\
(0.15)\end{array}$ & $\begin{array}{l}0.28^{*} \\
(0.10)\end{array}$ & $\begin{array}{c}0.08 \\
(0.05)\end{array}$ & $\begin{array}{l}0.26^{*} \\
(0.12)\end{array}$ \\
\hline$\hat{b}$ & $\begin{array}{c}0.40^{\dagger} \\
(0.23)\end{array}$ & $\begin{array}{l}0.88^{*} \\
(0.29)\end{array}$ & $\begin{array}{l}1.98^{*} \\
(0.81)\end{array}$ & $\begin{array}{l}0.65 \\
(1.02)\end{array}$ & $\begin{array}{l}0.90^{*} \\
(0.35)\end{array}$ \\
\hline$\hat{c}$ & $\begin{array}{l}0.89^{*} \\
(0.19)\end{array}$ & $\begin{array}{l}0.73^{*} \\
(0.26)\end{array}$ & $\begin{array}{l}-0.02 \\
(0.59)\end{array}$ & $\begin{array}{c}0.46 \\
(0.66)\end{array}$ & $\begin{array}{c}0.55 \\
(0.37)\end{array}$ \\
\hline$\hat{d}$ & $\begin{array}{l}0 \\
-\end{array}$ & $\begin{array}{l}10.17^{*} \\
(3.00)\end{array}$ & $\begin{array}{l}21.05^{*} \\
(7.34)\end{array}$ & $\begin{array}{l}29.10^{\dagger} \\
(15.07)\end{array}$ & $\begin{array}{l}17.87^{*} \\
(6.21)\end{array}$ \\
\hline \multirow{2}{*}{$\begin{array}{l}J \text { statistic } \\
\text { d.f. }\end{array}$} & 6.00 & 10.76 & 10.17 & 12.67 & 11.69 \\
\hline & 8 & 13 & 13 & 13 & 13 \\
\hline \multicolumn{6}{|c|}{ Panel B. Using (minus) Unemployment Gap } \\
\hline$\hat{a}$ & $\begin{array}{l}0.52^{*} \\
(0.23)\end{array}$ & $\begin{array}{l}0.13^{\dagger} \\
(0.08)\end{array}$ & $\begin{array}{l}0.15^{\dagger} \\
(0.08)\end{array}$ & $\begin{array}{c}0.13 \\
(0.08)\end{array}$ & $\begin{array}{l}0.15^{\dagger} \\
(0.08)\end{array}$ \\
\hline$\hat{b}$ & $\begin{array}{l}2.75^{*} \\
(1.38)\end{array}$ & $\begin{array}{l}4.06^{*} \\
(1.97)\end{array}$ & $\begin{array}{l}4.52^{*} \\
(2.16)\end{array}$ & $\begin{array}{l}6.74^{*} \\
(3.24)\end{array}$ & $\begin{array}{l}3.40^{*} \\
(1.45)\end{array}$ \\
\hline$\hat{c}$ & $\begin{array}{l}0.74^{*} \\
(0.24)\end{array}$ & $\begin{array}{c}0.43 \\
(0.46)\end{array}$ & $\begin{array}{c}0.72 \\
(0.46)\end{array}$ & $\begin{array}{c}0.59 \\
(0.52)\end{array}$ & $\begin{array}{c}0.57 \\
(0.36)\end{array}$ \\
\hline$\hat{d}$ & - & $\begin{array}{l}17.38^{*} \\
(7.10)\end{array}$ & $\begin{array}{l}17.85^{*} \\
(7.10)\end{array}$ & $\begin{array}{l}22.41^{*} \\
(9.74)\end{array}$ & $\begin{array}{l}16.86^{*} \\
(6.07)\end{array}$ \\
\hline$J$ statistic & 7.05 & 9.87 & 10.20 & 9.43 & 9.90 \\
\hline d.f. & 8 & 13 & 13 & 13 & 13 \\
\hline
\end{tabular}

Notes: The figures in parenthesis are standard errors. The instruments are a constant and six lags of the variables in the estimated rule. d.f. stands for degrees of freedom. The superscripts ${ }^{*}$ and ${ }^{\dagger}$ denote the rejection of the hypothesis that the true coefficient is zero at the 5 percent and 10 percent significance levels, respectively. 
Table 5. Estimated Reaction Functions

Quarterly Data

Pre-Volcker

\begin{tabular}{|c|c|c|c|c|c|}
\hline \multirow[b]{3}{*}{ Coefficient } & \multicolumn{5}{|c|}{ Nonlinear } \\
\hline & \multirow[b]{2}{*}{$\begin{array}{l}\text { Linear } \\
(1)\end{array}$} & \multirow[b]{2}{*}{$\begin{array}{c}\text { Baseline } \\
(2)\end{array}$} & \multicolumn{2}{|c|}{ Forward $(q, k)$} & \multirow[b]{2}{*}{$\begin{array}{c}\text { Backward } \\
(5)\end{array}$} \\
\hline & & & $\begin{array}{c}(1,1) \\
(3)\end{array}$ & $\begin{array}{c}(1,2) \\
(4)\end{array}$ & \\
\hline \multicolumn{6}{|c|}{ Panel A. Using IPI Gap } \\
\hline \multirow[t]{2}{*}{$\hat{a}$} & $0.58^{*}$ & 0.43 & $0.99^{*}$ & $1.00^{*}$ & $0.72^{*}$ \\
\hline & $(0.15)$ & $(0.29)$ & $(0.24)$ & $(0.27)$ & $(0.22)$ \\
\hline \multirow[t]{2}{*}{$\hat{b}$} & 1.07 & 2.97 & $0.31^{*}$ & $0.29^{\dagger}$ & $0.94^{*}$ \\
\hline & $(0.66)$ & $(6.56)$ & $(0.11)$ & $(0.16)$ & $(0.30)$ \\
\hline \multirow[t]{2}{*}{$\hat{c}$} & $0.49^{\dagger}$ & -0.77 & $1.14^{*}$ & $1.21^{*}$ & 0.36 \\
\hline & $(0.28)$ & $(4.49)$ & $(0.12)$ & $(0.20)$ & $(0.27)$ \\
\hline \multirow[t]{2}{*}{$\hat{d}$} & - & 1.41 & $-1.46^{*}$ & $-1.87^{*}$ & 0.59 \\
\hline & & $(5.99)$ & $(0.43)$ & $(0.73)$ & $(0.74)$ \\
\hline \multirow{2}{*}{$\begin{array}{l}J \text { statistic } \\
\text { d.f. }\end{array}$} & 6.59 & 8.31 & 4.09 & 5.51 & 7.22 \\
\hline & 4 & 7 & 7 & 7 & 7 \\
\hline \multicolumn{6}{|c|}{ Panel B. Using (minus) Unemployment Gap } \\
\hline \multirow[t]{2}{*}{$\hat{a}$} & $0.68^{*}$ & $0.73^{*}$ & $-0.99^{*}$ & $1.08^{*}$ & $0.87^{*}$ \\
\hline & $(0.16)$ & $(0.21)$ & $(0.21)$ & $(0.27)$ & $(0.26)$ \\
\hline \multirow[t]{2}{*}{$\hat{b}$} & $3.21^{*}$ & $3.82^{*}$ & $1.55^{*}$ & $1.57^{*}$ & $3.52^{*}$ \\
\hline & $(0.91)$ & (1.48) & $(0.43)$ & $(0.77)$ & $(0.65)$ \\
\hline \multirow[t]{2}{*}{$\hat{c}$} & $0.71^{*}$ & $0.63^{*}$ & $1.04^{*}$ & $1.14^{*}$ & $0.46^{*}$ \\
\hline & $(0.11)$ & $(0.26)$ & $(0.12)$ & $(0.20)$ & $(0.15)$ \\
\hline \multirow[t]{2}{*}{$\hat{d}$} & - & 0.05 & $-1.04^{*}$ & $-1.59^{*}$ & 0.64 \\
\hline & & $(0.57)$ & $(0.39)$ & $(0.66)$ & $(0.48)$ \\
\hline$J$ statistic & 7.03 & 6.96 & 4.60 & 4.56 & 6.26 \\
\hline d.f. & 4 & 7 & 7 & 7 & 7 \\
\hline
\end{tabular}

Notes: The figures in parenthesis are standard errors. The instruments are a constant and four lags of the variables in the estimated rule. d.f. stands for degrees of freedom. The superscripts ${ }^{*}$ and ${ }^{\dagger}$ denote the rejection of the hypothesis that the true coefficient is zero at the 5 percent and 10 percent significance levels, respectively. 
Table 6. Estimated Reaction Functions

Quarterly Data

Volcker-Greenspan

\begin{tabular}{|c|c|c|c|c|c|}
\hline \multirow[b]{3}{*}{ Coefficient } & \multirow[b]{3}{*}{$\begin{array}{c}\text { Linear } \\
(1)\end{array}$} & \multicolumn{3}{|c|}{ Nonlinear } & \multirow[b]{3}{*}{$\begin{array}{c}\text { Backward } \\
(5)\end{array}$} \\
\hline & & & Forwar & $\mathrm{d}(q, k)$ & \\
\hline & & $\begin{array}{l}\text { Baseline } \\
\text { (2) }\end{array}$ & $\begin{array}{c}(1,1) \\
(3)\end{array}$ & $\begin{array}{c}(1,2) \\
(4)\end{array}$ & \\
\hline \multicolumn{6}{|c|}{ Panel A. Using IPI Gap } \\
\hline$\hat{a}$ & $\begin{array}{l}-0.12 \\
(0.20)\end{array}$ & $\begin{array}{c}-0.99^{\dagger} \\
(0.56)\end{array}$ & $\begin{array}{c}-0.96^{*} \\
(0.44)\end{array}$ & $\begin{array}{c}-0.78^{\dagger} \\
(0.40)\end{array}$ & $\begin{array}{c}0.62^{\dagger} \\
(0.33)\end{array}$ \\
\hline$\hat{b}$ & $\begin{array}{c}0.76^{\dagger} \\
(0.44)\end{array}$ & $\begin{array}{l}0.51^{*} \\
(0.11)\end{array}$ & $\begin{array}{l}0.72^{*} \\
(0.19)\end{array}$ & $\begin{array}{l}1.03^{*} \\
(0.24)\end{array}$ & $\begin{array}{l}0.51^{*} \\
(0.15)\end{array}$ \\
\hline$\hat{c}$ & $\begin{array}{l}2.96^{*} \\
(0.75)\end{array}$ & $\begin{array}{l}1.18^{*} \\
(0.23)\end{array}$ & $\begin{array}{l}1.22^{*} \\
(0.27)\end{array}$ & $\begin{array}{l}0.90^{*} \\
(0.39)\end{array}$ & $\begin{array}{l}0.73^{*} \\
(0.23)\end{array}$ \\
\hline$\hat{d}$ & - & $\begin{array}{l}5.44^{*} \\
(1.13)\end{array}$ & $\begin{array}{l}5.43^{*} \\
(1.53)\end{array}$ & $\begin{array}{l}6.25^{*} \\
(2.06)\end{array}$ & $\begin{array}{l}1.00 \\
(2.20)\end{array}$ \\
\hline$J$ statistic & 5.72 & 3.89 & 5.05 & 8.22 & 8.91 \\
\hline d.f. & 4 & 7 & 7 & 7 & 7 \\
\hline \multicolumn{6}{|c|}{ Panel B. Using (minus) Unemployment Gap } \\
\hline$\hat{a}$ & $\begin{array}{c}-0.19^{*} \\
(0.26)\end{array}$ & $\begin{array}{l}-0.44 \\
(0.39)\end{array}$ & $\begin{array}{c}-0.87 \\
(0.63\end{array}$ & $\begin{array}{c}-1.42^{*} \\
(0.55)\end{array}$ & $\begin{array}{c}0.36 \\
(0.33)\end{array}$ \\
\hline$\hat{b}$ & $\begin{array}{c}2.36^{\dagger} \\
(1.37)\end{array}$ & $\begin{array}{l}2.91^{*} \\
(0.76)\end{array}$ & $\begin{array}{l}2.86^{*} \\
(0.80)\end{array}$ & $\begin{array}{l}2.74^{*} \\
(0.66)\end{array}$ & $\begin{array}{l}2.17^{*} \\
(0.58)\end{array}$ \\
\hline$\hat{c}$ & $\begin{array}{c}3.08^{*} \\
(0.76)\end{array}$ & $\begin{array}{l}1.14^{*} \\
(0.35)\end{array}$ & $\begin{array}{l}0.89^{*} \\
(0.22)\end{array}$ & $\begin{array}{c}1.03^{\dagger} \\
(0.52)\end{array}$ & $\begin{array}{c}0.37 \\
(0.28)\end{array}$ \\
\hline$\hat{d}$ & - & $\begin{array}{l}4.81^{*} \\
(1.57)\end{array}$ & $\begin{array}{l}5.39^{*} \\
(1.13)\end{array}$ & $\begin{array}{l}6.88^{*} \\
(2.05)\end{array}$ & $\begin{array}{c}3.18 \\
(2.19)\end{array}$ \\
\hline$J$ statistic & 4.35 & 5.82 & 4.20 & 7.78 & 8.87 \\
\hline d.f. & 4 & 7 & 7 & 7 & 7 \\
\hline
\end{tabular}

Notes: The figures in parenthesis are standard errors. The instruments are a constant and four lags of the variables in the estimated rule. d.f. stands for degrees of freedom. The superscripts ${ }^{*}$ and ${ }^{\dagger}$ denote the rejection of the hypothesis that the true coefficient is zero at the 5 percent and 10 percent significance levels, respectively. 
Table 7. Results OLS Regression

\begin{tabular}{|c|c|c|c|c|}
\hline \multirow[b]{2}{*}{ Coefficient on } & \multicolumn{2}{|c|}{ Monthly Data } & \multicolumn{2}{|c|}{ Q Quarterly Data } \\
\hline & $\begin{array}{c}\text { Pre-Volcker } \\
(1) \\
\end{array}$ & $\begin{array}{c}\text { Volcker-Greenspan } \\
(2) \\
\end{array}$ & $\begin{array}{c}\text { Pre-Volcker } \\
(3) \\
\end{array}$ & $\begin{array}{c}\text { Volcker-Greenspan } \\
(4)\end{array}$ \\
\hline Constant & $\begin{array}{c}0.63^{*} \\
(0.30)\end{array}$ & $\begin{array}{l}2.62^{*} \\
(0.19)\end{array}$ & $\begin{array}{l}2.32^{*} \\
(0.33)\end{array}$ & $\begin{array}{l}-0.58 \\
(1.13)\end{array}$ \\
\hline$\sigma_{\pi}^{2}$ & $\begin{array}{l}-3.83 \\
(2.34)\end{array}$ & $\begin{array}{l}7.03^{*} \\
(1.92)\end{array}$ & $\begin{array}{r}-0.94^{*} \\
(0.17)\end{array}$ & $\begin{array}{l}4.15^{*} \\
(1.06)\end{array}$ \\
\hline
\end{tabular}

Notes: The figures in parenthesis are standard errors. The superscripts ${ }^{*}$ and ${ }^{\dagger}$ denote the rejection of the hypothesis that the true coefficient is zero at the 5 percent and 10 percent significance levels, respectively. 


\section{A Appendix}

This Appendix derives the optimal monetary policy rule when preferences are asymmetric and the supply curve is nonlinear. The central bank is assumed to implement monetary policy using the nominal interest rate as instrument. The dynamic problem of the central bank [see eq. (1) in text] can be decomposed into the sequence of period-by-period problems:

$$
\begin{aligned}
& \operatorname{Min} \\
& \left\{i_{t}\right\}
\end{aligned}
$$

subject to

$$
\begin{aligned}
y_{t+1} & =\delta y_{t}-r_{t}+\eta x_{t}, \\
\pi_{t+1} & =\pi_{t}+f\left(y_{t}\right)+u_{t+1}
\end{aligned}
$$

where $f\left(y_{t}\right)=\alpha y_{t} /\left(1-\alpha \phi y_{t}\right), x_{t+1}=\psi x_{t}+e_{t+1}$, and $i_{t}=r_{t}+E_{t} \pi_{t+1}$, with all notation as defined in the text. In order to derive the first-order condition, apply the chain rule:

$$
\begin{aligned}
E_{t}\left(\left(\partial L_{t+2} / \partial \pi_{t+2}\right)\left(\partial \pi_{t+2} / \partial y_{t+1}\right)\left(\partial y_{t+1} / \partial r_{t}\right)\left(\partial r_{t} / \partial i_{t}\right)\right) & =0 \\
-\alpha\left(\exp \left(\gamma E_{t}\left(\pi_{t+2}-\pi^{*}\right)+\left(\gamma^{2} / 2\right) \sigma_{\pi, t}^{2}\right)-1\right) /\left(\gamma\left(1-\alpha \phi y_{t+1}\right)^{2}\right) & =0
\end{aligned}
$$

This condition is satisfied if and only if:

$$
E_{t} \pi_{t+2}=\pi^{*}-\gamma \sigma_{\pi, t}^{2} / 2
$$

But, from the aggregate supply relation

$$
\begin{aligned}
E_{t} \pi_{t+2} & =E_{t}\left(\pi_{t+1}+f\left(y_{t+1}\right)+u_{t+2}\right), \\
& =E_{t}\left(\pi_{t}+f\left(y_{t}\right)+f\left(y_{t+1}\right)+u_{t+2}+u_{t+1}\right), \\
& =\pi_{t}+\alpha y_{t} /\left(1-\alpha \phi y_{t}\right)+\alpha\left(\delta y_{t}-r_{t}+\eta x_{t}\right) /\left(1-\alpha \phi\left(\delta y_{t}-r_{t}\right)\right) .
\end{aligned}
$$

Hence, it must be the case that

$$
\pi_{t+2}-\gamma \sigma_{\pi, t}^{2} / 2=\pi_{t}+\alpha y_{t} /\left(1-\alpha \phi y_{t}\right)+\alpha\left(\delta y_{t}-r_{t}+\eta x_{t}\right) /\left(1-\alpha \phi\left(\delta y_{t}-r_{t}\right)\right)
$$

Solving for $r_{t}$ :

$$
r_{t}=\delta y_{t}+\frac{\left(\pi_{t}-\pi^{*}+\gamma \sigma_{\pi, t}^{2} / 2+f\left(y_{t}\right)\right)}{\alpha\left(1-\phi\left(\pi_{t}-\pi^{*}+\gamma \sigma_{\pi, t}^{2} / 2+f\left(y_{t}\right)\right)\right)}+\eta x_{t} .
$$

Substituting into the Fisher equation, using $E_{t} \pi_{t+1}=\pi_{t}+f\left(y_{t}\right)$, and simplifying:

$$
i_{t}=\pi_{t}+f\left(y_{t}\right)+\delta y_{t}+\frac{(1 / \alpha)\left(\pi_{t}-\pi^{*}+\gamma \sigma_{\pi, t}^{2} / 2+f\left(y_{t}\right)\right)}{1-\phi\left(\pi_{t}-\pi^{*}+\gamma \sigma_{\pi, t}^{2} / 2+f\left(y_{t}\right)\right)}+\eta x_{t}
$$


that corresponds to expression (8) reported in the text.

If a quadratic output-stabilization term were to be added to the central bank's loss function, the new function would be

$$
L\left(\pi_{t}-\pi^{*}, y_{t}\right)=\frac{\left.\left.\exp \left(\gamma\left(\pi_{t}-\pi^{*}\right)\right)-\gamma\left(\pi_{t}-\pi^{*}\right)-1\right)\right)}{\gamma^{2}}+\lambda y_{t}^{2}
$$

where $\lambda>0$ measures the importance of output stabilization. The minimization of this function subject to the same set of constraints is discussed in detail in Svensson (1997). Svensson (see Appendix B) proposes to study first the simpler problem represented by the Bellman equation.

$$
V\left(\pi_{t}\right)=\min _{\left\{y_{t}\right\}}\left\{\frac{\left.\left.\exp \left(\gamma\left(\pi_{t}-\pi^{*}\right)\right)-\gamma\left(\pi_{t}-\pi^{*}\right)-1\right)\right)}{\gamma^{2}}+\lambda y_{t}^{2}+\beta E_{t} V\left(\pi_{t+1}\right)\right\},
$$

subject to $\pi_{t+1}=\pi_{t}+f\left(y_{t}\right)+u_{t+1}$, where the output gap is the control variable and, for simplicity, we will assume that $\phi=0$, meaning $f\left(y_{t}\right)=\alpha y_{t}$. When $\gamma \rightarrow 0$, the value function will be quadratic: $V\left(\pi_{t}\right)=k_{0}+k_{1}\left(\pi_{t}-\pi^{*}\right)^{2}$. The coefficient $k_{1}$ can be found analytically using the envelope theorem. When $\gamma \neq 0$, the value function will have the linex form:

$$
V\left(\pi_{t}\right)=k_{0}+k_{1} \frac{\exp \left(\gamma\left(\pi_{t}-\pi^{*}\right)\right)-\gamma\left(\pi_{t}-\pi^{*}\right)-1}{\gamma^{2}}
$$

The envelop theorem implies

$$
\begin{aligned}
V_{\pi}\left(\pi_{t}\right) & =k_{1} \frac{\exp \left(\gamma\left(\pi_{t}-\pi^{*}\right)\right)-1}{\gamma} \\
E_{t} V_{\pi}\left(\pi_{t+1}\right) & =k_{1} \frac{\exp \left(\gamma\left(E_{t} \pi_{t+1}-\pi^{*}\right)+\gamma^{2} \sigma_{\pi, t}^{2} / 2\right)-1}{\gamma}
\end{aligned}
$$

It is not hard to verify that a closed-form expression for $\mathrm{k}_{1}$ does not exist. Consequently, a closed-form expression for the policy rule does not exist either. 


\section{References}

[1] Alvarez-Lois, P (2001), "Asymmetries in the Capacity-Inflation Trade-Off" Universidad Autónoma de Barcelona. Mimeo.

[2] Blinder, A. S. (1998), Central Banking in Theory and Practice, The MIT Press: Cambridge.

[3] Clarida, R., Gali, J., and Gertler, M. (1997), "Monetary Policy Rules in Practice: Some International Evidence," European Economic Review, 42: 1033-1067.

[4] Clarida, R., Gali, J., and Gertler, M. (1999), "The Science of Monetary Policy: A New Keynesian Perspective," Journal of Economic Literature, 37: 1661-1707.

[5] Clarida, R., Gali, J., and Gertler, M. (2000), "Monetary Policy Rules and Macroeconomic Stability: Evidence and Some Theory," Quarterly Journal of Economics, 115: $147-180$.

[6] Clark, P., and Laxton, D. (1996), "Phillips Curves, Phillips Lines, and the Unemployment Costs of Overheating", International Monetary Fund, Mimeo.

[7] Cukierman, A. (2000), "The Inflation Bias Result Revisited ," Tel-Aviv University, Mimeo.

[8] Dolado, J. J., María-Dolores, R., and Naveira, M. (2001), "Are Monetary Policy Rules Asymmetric?: Evidence for Some Central Banks," Universidad Carlos III, Mimeo.

[9] Gallant, R. A., Rossi, P. E., and Tauchen, G. (1993), "Nonlinear Dynamic Structures," Econometrica, 61: 871-908.

[10] Gerlach, S. (2000), "Asymmetric Policy Reactions and Inflation," Bank for International Settlements, Mimeo.

[11] Kimball, M. S. (1990), "Precautionary Savings in the Small and the Large," Econometrica, 58: 53-73.

[12] Koop, G., Pesaran, M. H., and Potter, S. M. (1996), "Impulse Response Analysis in Nonlinear Multivariate Models," Journal of Econometrics, 74: 119-147.

[13] Layard, R., Nickell, S., and Jackman, R. (1991), Unemployment, Oxford University Press: Oxford, New York. 
[14] McCallum, B. T. (1995), "Two Fallacies Concerning Central Bank Independence," American Economic Review Papers and Proceedings, 85: 201-211.

[15] McCallum, B. T. (1997), "Crucial Issues Concerning Central Bank Independence," Journal of Monetary Economics, 39: 99-112.

[16] Nobay, R. A. and Peel, D. A. (1998), "Optimal Monetary Policy in a Model of Asymmetric Central Bank Preferences," London School of Economics, Mimeo.

[17] Nobay, R. A. and Peel, D. A. (2000), "Optimal Monetary Policy with a Nonlinear Phillips Curve," Economics Letters, 67: 159-164.

[18] Pagan, A. (1984), "Econometric Issues in the Analysis of Regressions with Generated Regressors," International Economic Review, 25: 221-247.

[19] Pagan, A. and Ullah, A. (1988), "The Econometric Analysis of Models with Risk Terms," Journal of Applied Econometrics, 3:87-105.

[20] Ruge-Murcia, F. J. (2001), "A Prudent Central Banker," IMF Staff Papers, forthcoming.

[21] Ruge-Murcia, F. J. (2002), "The Inflation Bias when the Central Banker Targets the Natural Rate of Unemployment," European Economic Review, forthcoming.

[22] Schaling, E. (1999), "The Nonlinear Phillips Curve and Inflation Forecast Targeting," Bank of England, Working Paper No. 98.

[23] Svensson, L. E. O. (1997), "Inflation Forecast Targeting: Implementing and Monitoring Inflation Targets," European Economic Review, 41: 1111-1146.

[24] Varian, H. (1974), "A Bayesian Approach to Real Estate Assessment," in Studies in Bayesian Economics in Honour of L. J. Savage, edited by S. E. Feinberg and A Zellner. North-Holland: Amsterdam. 
Fig. 1. Relation between the Real Interest Rate and the Conditional Variance of Inflation 1960:I to 1979:II

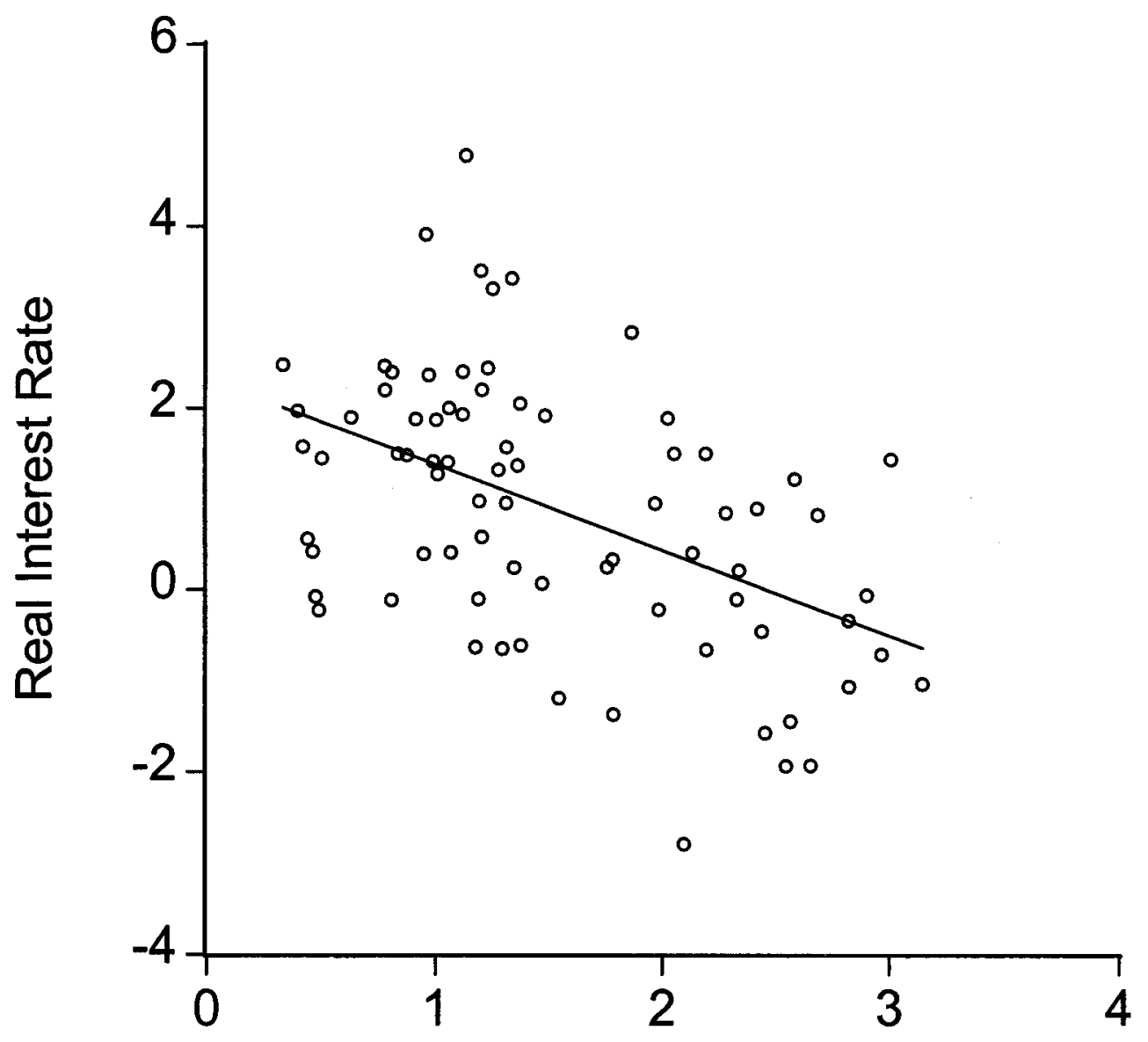

Conditional Variance 
Fig. 2. Relation between the Real Interest Rate and the Conditional Variance of Inflation 1983:I to 2000:IV

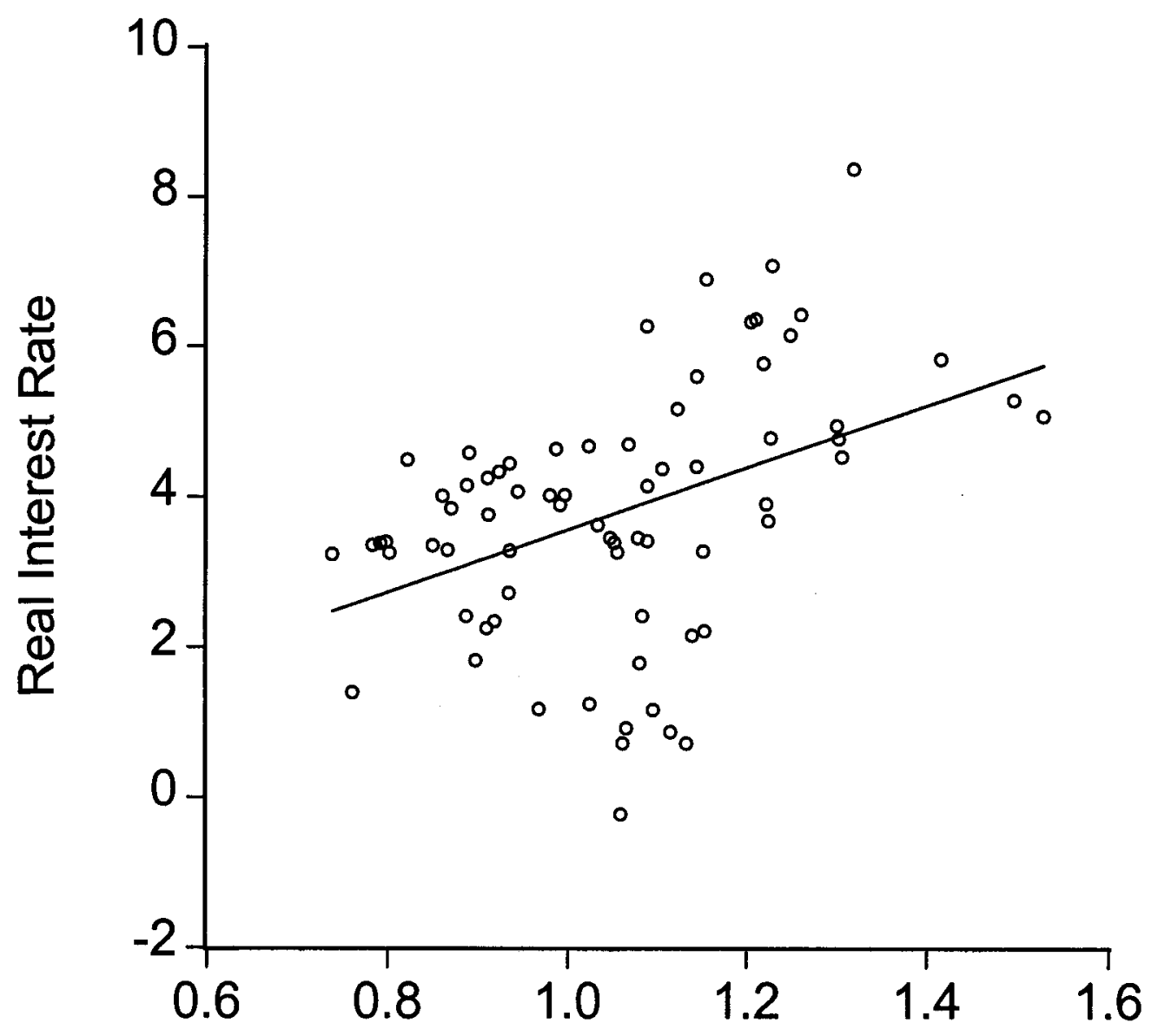

Conditional Variance 